\title{
UNA ECONOMÍA TENTACULAR. LA RELACIÓN ECONÓMICA MURCIA-ORIHUELA EN LOS FINALES DEL SIGLO XIV
}

\author{
M. a DE LOS LLANOS MARTÍNEZ CARRILLO \\ Universidad de Murcia
}

La muerte de Pedro I en Montiel en 1369 después de muchos años de guerra civil en Castilla, y muchos más de graves alteraciones del sistema económico social de occidente del que aquella participó, dio paso a una nueva dinastía caracterizada en sus primeros eslabones por los intentos de reconstrucción proyectados para Castilla y solamente en parte realizados; la economía fue un pilar fundamental de esa política de los nuevos reyes Trastámaras, como lo habia sido en las destructivas etapas anteriores, porque el cambio dinástico se iniciaba sobre unas bases agostadas por la doble acción de una profunda crisis económica y las consecuencias internacionales de la guerra civil, según las cuales el nuevo rey, Enrique II, se vio en la necesidad de tener que saldar las fuertes deudas contraidas con los contingentes militares extranjeros, que le habian ayudado a alcanzar el trono de la forma más rápida y expeditiva posible.

La crónica es sumamente gráfica: «el rey don Enrique, estando en Toledo, ovo su consejo, que por quanto avia de facer grandes pagas a mosen Beltran, é a los estrangeros que con él vinieron, é otro si á los suyos, que non lo podia complir, por grandes pechos que en el Regno echase; de más que su voluntad era de guardar e non enojar á muchas comarcas del Regno que tovieron su voz. E por todo esto, acordo de mandar labrar moneda...» (1)

Para el nuevo rey castellano, la imposibilidad de derramar los impuestos necesarios para saldar la totalidad de las deudas, sin poner a prueba las deterioradas bases sociales del reino, lo obligó a encadenar una serie de acuñaciones monetarias claramente devaluatorias (2), que le permitiesen pagar sin agotar más, si ello era posible, una economía casi paralizada. 
El cronista localiza en Toledo la inicial toma de decisiones por parte de Enrique II para organizar la acuñación de nuevas monedas con las que poder saldar cuentas con los extranjeros y hacerles salir del reino inmediatamente, una vez culminada su ayuda militar, pero la documentación existente permite retrotraerlas a su previa estancia en Sevilla, cuando se dio cuenta de que el petrismo era una fuerza y un sentimiento no extinguidos, a los que una torpe política económica de derramas fiscales podría proporcionar nuevos impulsos; no habia más salida que reorganizar el sistema monetario y fue en mayo de 1369 en Sevilla, donde el rey arrendaba las casas de moneda y organizaba las nuevas acuñaciones (3).

Las casas de la moneda afectadas por el arrendamiento eran las de Sevilla, Córdoba y Murcia (4), aunque en el caso de esta última al rey se le presentaba un importante problema de seguridad; si bien el 24 de marzo, inmediatamente después de la muerte de Pedro I, comunicaba al concejo murciano el nombramiento de Juan Sánchez Manuel, conde de Carrión, como nuevo adelantado mayor del reino de Murcia (5), la inestabilidad en este territorio de la Corona era muy fuerte por la ayuda y cobijo que los petristas recibian en el muy próximo territorio de la gobernación de Orihuela y en general en toda la Corona Catalano-Aragonesa, desde donde continuaron operando algún tiempo de tal manera que, en la mente de Enrique II, Murcia no estaba firmemente asegurada y el funcionamiento de su ceca se presentaba problemático.

A las dificultades encontradas para la reconstrucción, generales a toda Castilla, en el reino murciano había que contar además con la política, anexionista unas veces y perturbadora otras, que practicaba respecto al mismo Pedro IV de Aragón, quien siempre aprovechó la ayuda prestada a Enrique de Tratámara para intentar recobrar en pago de ella el reino de Murcia (6); la frustración de estas pretensiones fue un factor más a tener en cuenta en el endurecimiento económico desarrollado a lo largo del reinado de Enrique II, convirtiendo lo que tradicionalmente fue un proteccionismo mercantil en la primera mitad del siglo XIV, en una casi completa autarquía a nivel murciano.

La misma proximidad a la frontera aragonesa había convertido a Murcia en plaza aduanera permanente en la administración castellana desde el siglo XIII, juntamente con Cartagena en la costa, y a partir de la entronización de Enrique II en ella se acusó el refuerzo de las prohibiciones que tradicionalmente pesaron sobre la exportación de caballos, cualquier tipo de ganados de tiro o arada, armas, cereales y monedas, cuya salida a territorio aragonés había sido muy frecuente durante la guerra y continuaría siéndolo de forma clandestina en los años siguientes (7), a pesar de la tajante prohibición de que 
fue objeto. El enrarecimiento de la frontera fue tan radical a partir de 1370 que el oriolano Francés Dexines tuvo que pedir un seguro especial al concejo murciano, para poder venir a vender en Murcia paños y vidrios y tener «casa cierta» en la ciudad (8) y solamente se le concedió cuando el adelantado mayor hubo dado su aprobación para ello.

Este cúmulo de circunstancias generales y regionales dieron lugar a un global empobrecimiento del comercio murciano, al que contribuyó en buena medida el rechazo de que era objeto entre la población la moneda devaluada que se estaba acuñando y la entrada cada vez más intensa de moneda falsa castellana acuñada en Aragón.

\section{INCIDENCIA DE LAS DEVALUACIONES}

En 1371, al año de que las cortes de Medina del Campo de 1370 fijaran el valor de las monedas un tercio por debajo del que habian tenido anteriormente, la nueva moneda apenas tenía circulación en Murcia, pues «...las gentes desta çibdad que desechaban mucha de la moneda de los reales asy de los que eran buenos como de los otros y por esto era encareçido el pan y el vino $y$ todas las otras cosas que las gentes avian menester para su provisyon...» (9); la introducción de veedores de las monedas ordenada en las cortes de Toro de 1371 y la decisión de taladrar todos los reales que tuviesen un valor superior al establecido, fueron medidas tendentes a regular el caos monetario que en la economía regional se estaba sintiendo, y sus consecuencias inmediatas de elevación de precios en un medio social políticamente no fortalecido.

Los arrendadores de rentas reales fueron un elemento básico en el funcionamiento del sistema monetario, al exigir con contundencia que los cobros se hiciesen en cruzados y no admitir los valores del real ordenados en 1370 , buscando con ello el no verse afectados por las falsificaciones aragonesas de reales que inundaban los mercados del reino. Igualmente la Iglesia rechazaba con rigor cobrar sus censos en la moneda de plata devaluada, obligando a los censatarios a «...que les den dinero en oro...» (10), mucho más seguro en su valor.

La presencia del adelantado mayor Juan Sánchez Manuel fue fundamental en la marcha de la economía del reino en estos años, sobre todo a partir de la fijación de valores efectuada en las cortes de Toro de 1373 que elevaba al valor de las monedas, una vez saldadas las deudas internacionales que habian dado origen a las devaluaciones anteriores. Las rentas que cobraba de sus tierras y oficios se estaban viendo afectadas por el proceso inflaccionista, y la falta de productividad general y el empobrecimiento le salpicaban 
de lleno; su actuación económica compensatoria de este hecho fue muy intensa y se manifiesta claramente a través de la obtención de su despensero mayor, el judío Moisés Aventuriel, del arrendamiento de los almojarifazgos del reino entre 1371 y 1374 sin que se pueda delimitar textualmente sí el judío actuaba por sí mismo o como hilo conductor de los intereses del adelantado mayor, pero el estar encargado de la recaudación el también canciller del conde Juan Martínez y los problemas que encontró en la ciudad para cobrar los derechos correspondientes (11), permiten deducir que era el conde de $\mathrm{Ca}$ rrión el vértice superior del arrendamiento, y que en él confluían todos los derechos paramercantiles del almojarifazgo.

Ésta y otras intervenciones económicas del conde de Carrión produjeron su inmediato rechazo por parte de los murcianos (12) a partir de la entrada en vigor de los nuevos y más altos valores monetarios de 1373, como consecuencia de una fuerte desconfianza hacia su persona despertada por las oportunistas maniobras económicas del conde, y ahondada por la lejanía murciana respecto a los centros neurálgicos de la economia castellana; todo ello junto a la pobreza general del territorio, si se excluye el área regada por el Segura, explica el que la economía tuviese en aquellos años en el reino de Murcia unas característcas puramente tentaculares respecto a la general de la corona de Castilla.

La moneda de 1373, la «moneda nueva», de valor reforzado respecto a la devaluadísima de las primeras acuñaciones enriqueñas, la «moneda viejam, como empezaron a ser diferenciadas unas y otras, no tuvo tampoco una implantación drástica y clara en la economía del reino, por lo que la utilización de unas y otras de forma simultánea contribuye aún más a complicar el análisis de las tendencias económicas de aquellos años.

\section{MONEDA FALSA Y MONEDA NO CASTELLANA}

Junto a la moneda real tan duramente afectada por la política de intereses dinásticos de Enrique II, en Murcia se apreció desde los comienzos del reinado un uso creciente de moneda falsa, lo cual fue un fenómeno general al siglo XIV derivado del impacto que estaba produciendo el desmesurado uso de monedas en economías de muy bajo nivel de producción; en 1371 su circulación era tan abundante y perturbadora, que el concejo murciano ordenaba su embargo al «alcalde de las monedas» y a un notario auxiliar, para proceder judicialmente contra los culpables de introducirlas o utilizarlas deliberadamente en cualquier tipo de operación económica.

El paso siguiente que se dio para tratar de depurar el sistema monetario, fue el nombramiento de dos «veedores de la moneda», Francisco Solsona y 
Pedro Fernández, para que recogiesen toda la que entraba fraudulentamente en el reino, contabilizándola y poniéndola «en buena arca» para que pudiesen ser descubiertos y apresados todos los que introdujesen reales, cruzados o cualquier otra moneda falsa procedente de Aragón, sin que pudiesen ser liberados hasta que el rey proveyese en consecuencia.

Eran sobre todo reales falsos las piezas que entraban de Aragón y «...de los otros que son buenos dudan mucho las gentes de tomar la moneda buena por la mala e por esto eran encareçidas las viandas y todas las otras cosas que los omes an mester para su mantenimiento y espeçialmente pan..." (14), por to que de la agudización de la crisis monetaria desatada por las devaluaciones y la abundancia de falsificaciones se derivaba un peligro despoblador del reino, siempre temido y nunca totalmente superado en Murcia; no hay en este caso exageración documental, al valorar la carestía existente en el pan y su escasez en la ciudad, a la que contribuía en gran medida la complejidad monetaria existente y su constante enrarecimiento.

El concejo murciano recurrió al rey buscando soluciones al problema de las falsificaciones que inundaban el mercado local procedentes de Aragón, reales, cruzados y coronados, sin que Enrique II pudiese hacer más que reiterar las medidas adoptadas apenas un mes antes, según las cuales se retirarían antes del 1 de enero de 1374 todas las oportunistas acuñaciones emitidas después de la guerra civil, dejando consecuentemente a los emisores de falsificaciones fuera de juego; los reales, cruzados y coronados asi retirados se refundirian con los valores de la moneda que circulaba antes de 1369, doblas de oro, reales de plata, coronados, sueldos, novenes y cinquenes (15).

Las falsificaciones efectuadas en Aragón recibian asi un fuerte golpe, a pesar de que contaban con todo el apoyo de Pedro IV tanto en su acuñación como en su circulación; el monarca aragonés les había utilizado muy hábilmente como peligrosa arma económica contra Castilla, donde producian inflacción y encarecimiento en el mercado que a su vez actuaban como fermentos de inestabilidad social, aparte de los beneficios intrínsecos que sus emisiones reportaban a la corona, calculados por Gil Farrés en más de 10.000 florines anuales (16), solamente con las acuñaciones falsas que salían de las cecas reales.

Pero no eran solamente las falsas monedas castellanas el único factor de perturbación económica procedente de Aragón que actuaba en la economía del reino murciano; es preciso tener en cuenta igualmente la fluidez con que la moneda aragonesa habia circulado siempre en territorio murciano, prociada sin duda por la complementariedad de intereses existentes con la veci- 
na ciudad de Orihuela y toda la cuenca baja del Segura, así como la marginalidad del reino Murciano respecto a los demás territorios de la Corona de Castilla.

Fue sobre todo en el reinado de Juan I, cuando la moneda aragonesa circuló en territorio murciano como moneda de uso ordinario que suplantaba a la castellana en infinidad de ocasiones; los testimonios de los arrendadores y recaudadores de rentas exigiendo moneda castellana en los cobros de las mismas, son elocuentes de la amplitud del fenómeno, que desde que en 1373 Enrique II había mandado retirar todas sus acuñaciones anteriores fijando definitivamente el valor del monedaje castellano, había ido en aumento: «...en esta dicha çibdat non ha nin viene otra moneda castellana salvo esta moneda de realejos de Aragón...», se decía en 1380 (17) ante una negativa de los recaudadores a admitirla.

Cabe plantearse si la intensidad del comercio con Aragón que facilitaba la entrada de esta moneda era de más valor y fluidez que la correspondiente al mantenido con los territorios castellanos del interior, si los factores de proximidad y homogeneidad geográficos pesaban más que el marco políticoinstitucional en el que el reino de Murcia estaba encuadrado y del que no recibia suficiente moneda cuando no era acuñada en la propia ciudad, tal como ocurría desde las últimas acuñaciones de Enrique II. La precariedad monetaria murciana era tal en los comienzos del reinado de Juan I, que el rey autorizó la recaudación de una derrama de monedas, en «...reales de Aragon que andan en el presçio y numero de los cornados castellanos...» a petición del concejo murciano (18), para que la escasez monetaria y las dificultades de pago de los murcianos derivadas en parte de ella, no contribuyesen a agravar las consecuencias sociales de la gran presión fiscal que pesaba sobre el reino.

A pesar de la autorización real, la resistencia de los recaudadores a admitir los reales aragoneses fue constante porque no era moneda tan usada en ningún otro territorio castellano, «...salvo a menos presçio de lo que alla vale...» (19); moneda infravalorada en toda Castilla respecto a Murcia como consecuencia de la crónica desmonetarización sufrida en esta ciudad, que era una de las razones de las constantes dificultades fiscales que Murcia y su reino vivieron; de ahi también la frecuencia con que el concejo buscaba créditos fuera del reino, tratando de encontrar los intereses más bajos posibles en Orihuela o en la propia Valencia (20).

El caso del florín no es comparable al de los «realejos» aragoneses; a pesar de su pérdida de valor desde las primeras acuñaciones ordenadas en 1346 
por Pedro IV, y de que sus falsificaciones también fueron frecuentes y no fáciles de detectar entonces y ahora (21), su utilización como moneda fuerte apreciada fue constante en el reino murciano, incluidas sus fracciones como el "seixmo" (22), que permitían en la cuantificación una más fácil acomodación a los valores pequeños que caracterizaban el mercado de productos, trabajo e impuestos en el que se movia la sociedad murciana.

Relacionado con el uso tan continuado que se hacía de la moneda aragonesa en el reino murciano estaba la fáctica supervaloración de las monedas de oro y plata castellanas, de circulación más restringida de lo normal en Murcia, en comparación a lo que valian en el resto de los territorios de la Corona Castellana (23):

Valores monetarios en maravedis correspondientes a 1384

\begin{tabular}{|c|c|c|c|}
\hline & $\begin{array}{c}\text { dobla } \\
\text { castellana }\end{array}$ & $\begin{array}{c}\text { dobla } \\
\text { morisca }\end{array}$ & $\begin{array}{c}\begin{array}{c}\text { florín } \\
\text { aragonés }\end{array} \\
\end{array}$ \\
\hline Murcia & 38 & 36 & 22 \\
\hline Resto de Castilla & 37 & 35 & 21 \\
\hline
\end{tabular}

De que las recaudaciones de impuestos se hiciesen utilizando los valores bajos, como pedian los recaudadores, que intentaba hacer buenos el concejo murciano, dependía una mayor o menor dificultad en las recaudaciones que el vecindario acusaba.

El alza de los valores en el mercado local fue una constante no enturbiada por las características hiperbólicas de la documentación; de los 21 maravedís que valía el florín de oro aragonés en los comienzos del reinado de Juan I se fue ascendiendo progresivamente, a tenor del mayor endeudamiento social y concejil, porque a mayores necesidades mayores exigencias de los prestamistas que acababan convirtiendo los valores extraordinarios del florín en otros puramente ordinarios: en 1387 el florín aragonés rebasaba los 22 maravedís, aún con sintomas evidentes de que muchos de ellos habian disminuido de peso y valor real, «...menguados et cerçenados en derredor...» (24).

La acentuación de la escasez y revaluación de las monedas fuertes de oro y plata y la depreciación del vellón fueron consecuencias de la guerra de Portugal y su gran coste económico, recrudeciéndose la crisis en los años ochenta lo que propició una nueva entrada de falsificaciones procedentes de Aragón en territorio murciano. Reactividas las falsificaciones al compás de las primeras acuñaciones de Juan I, realizadas en 1382 en Burgos y Sevilla (25), en mómentos en los que la devaluación daba lugar a un tirón ascendente de los precios, afectaron también al florín en su doble forma de falsificación total 
o alteración fraudulenta de peso y ley, precediendo el nombramiento concejil de Francisco Mallol como veedor a la orden real de que se investigase quienes eran los autores, si no materiales sí cómplices de la falsificación, para interceptar la difusión de esta moneda falsa, entre ella los florines aragoneses «...mucho faltos e menguados de peso...» (26).

En las cortes celebradas en Briviesca en 1387 se intentó poner un orden práctico en el desequilibrio económico monetario que la guerra de Portugal y sus compromisos posteriores acentuaron y agravaron; la devaluación de las blancas de 10 dineros que valían anteriormente a 6 «dineros llanos» (27), fue la medida económica más política de todas las adoptadas, al permitir automáticamente una bajada de precios y salarios.

\section{CONTROL ECONÓMICO DE LA FRONTERA}

Durante la guerra civil y los años inmediatamente posteriores, el comercio de Aragón se habia estado efectuando de forma clandestina y sin ningún tipo de contrapartida fiscal para la Corona Castellana, de tal modo que en 1373 y 1375 Enrique II ordenó la realización de dos investigaciones en la ciudad para averiguar quienes y cuántos habian sido los exportadores y repartir entre ellos dos cantidades complementarias en concepto de multas y derechos no pagados (28).

Los aproximados 400 y 1.800 maravedía que se pagaron respectivamente en ambas ocasiones no fueron sólo la multa impuesta por unas obligaciones no cumplidas con la administración de aduanas, sino que tuvieron más bien el carácter de un ensayo de reparto fiscal que intentaba regularizar y hacer ordinario el cobro de un impuesto sobre el comercio de exportación (29); si el sistema fracasó fue por su complejidad y las dificultades sociales que entrañaba al realizarse a través de unas enojosas pesquisas, individuo por individuo, símbolo de las cuales y del peligro social que encerraron fue la quema en el concejo de los testimonios escritos y toda la documentación complementaria de los dos padrones elaborados «... por que non pareciese dello cosa alguna por que escandalo nin peleas non acaesçiesen entre las gentes por esta rason..." (30). Los fraudes y ocultaciones que se hicieron por muchos afectados en la primera investigación forzaron a Enrique II a ordenar la segunda, a ampliar la cantidad a pagar que debía resultar ridícula dada la magnitud de lo exportado de forma clandestina.

Estos intentos de regulación fiscal de las aduanas del reino, con referencia a los cinco años transcurridos desde el final de la guerra civil, se producian en momentos en los que la política aduanera frente a Aragón se endure- 
cía en el marco de las consecuencias de la guerra castellano aragonesa, que había llevado a los murcianos a tomar el castillo de Crevillente mientras las propiedades de sus vecinos en Orihuela, Elche y Alicante eran embargadas (31). La guerra había empezado en marzo de 1375, pero desde septiembre del año anterior había sido perceptible en Murcia una corriente de avecindamiento en la ciudad de individuos procedentes de territorio valenciano, la mayoría de Orihuela; algunos vivían ya en Murcia algún tiempo como simples «moradores» dedicados a actividades mercantiles y si decidieron solicitar la vecindad en los momentos en que la tensión bélica amenazaba con romper la actividad económica de la que vivían, fue porque la misma se centraba más en Murcia que en sus tierras de origen, admitiéndoseles sin dificultades porque la presentación de fiadores y el capital que aportaban garantizaban que no serían gravosos con su estabilidad en Murcia.

Algunos como Bartolomé de Ávila que se avecindó procedente de Orihuela con un capital de 500 maravedís (32), habian sido en aquella ciudad vecinos de ocasión mientras sus actividades así lo requirieron, por el contrario Joaquín Cardona y su hijo que aportaban otros 500 maravedís, Miguel Sánchez (33), Antón Tomás, Juan Martínez y Elisey de Moncada, mujer de Alonso Jiménez de Mendieta, procedían originariamente de tierras catalanoaragonesas, que algunos dejaban con muchas dificultades, como Antón Tomás y sus hermanos que teniendo ya fiadores en Murcia, no recibieron permiso de Orihuela para dejar la ciudad hasta no quedar libres de compromisos en ella.

En los momentos de iniciarse la guerra con Aragón se añadieron a los anteriores un mínimo de 10 nuevos vecinos que presentaban capitales minimos de hasta 50 maravedís, entre los que se contaban individuos que en los años anteriores ya habian desempeñado actividades económicas en Murcia y que en adelante las seguirian desempeñando más intensamente como vecinos, tal fue el caso de Huguet de Soteros, Esteban de Pamiés y Jaime Terrés, cuyos negocios en el comercio de carnes y tintes en los años ochenta y noventa fueron muy continuos.

En estas condiciones, se llegó por parte castellana a la expulsión de los ganados aragoneses que pastaban en territorio murciano, decretada por Enrique II, porque además de explotar los pastizales eran utilizados para sacar cereales y otros ganados castellanos mezclados con ellos (34), paliando así el hambre padecida por entonces en Aragón y Valencia; era ésta una modalidad de comercio clandestino que sangraba la economía castellana en dirección al reino vecino, sin compensaciones algunas por lo que la prohibición 
fue total: «...de aqui adelante non consintades que ganados ningunos del regno de Aragon nin de Valençia entren a paçer en la nuestra tierra...»

A petición del concejo de Murcia el rey prohibía también la saca por vecinos y mercaderes aragoneses y genoveses de cualesquier productos vedados, caballos, armas, oro y plata, pan y ganados, que posiblemente eran los productos que en años inmediatos se habían estado exportando clandestinamente en mayor volumen; ellos traían sus mercancías a Murcia previamente y los productos de retorno eran estos vedados, en lugar de los permitidos y menos necesarios a la economía castellana, por tanto no vedados, lino, higos, miel, cera, etc. «...e que por esto viene danno a esa çibdat e que sy asy ouiese de pasar que se despoblaria por ello..." (35)

Desde 1374 la radical reglamentación del control aduanero hizo que aragoneses o genoveses viniesen menos a Murcia y que los cuatro productos citados que controladamente se podían exportar, no tuviesen venta, cuando eran productos que todos los vecinos poseían en cantidades variables; la excepción fue la saca del pan de forma coyuntural para traer del valle del Guadalquivir y cubrir así la gran necesidad atravesada por aquellos años en Murcia.

El bloquo de la frontera comercial con Orihuela en 1375 llegó a ser casi total al coincidir con una de las peores etapas de las relaciones castellanoaragonesas, y más tratándose de evitar el flujo de moneda cuya salida no podía justificarse, ni siquiera como ocasionada para abastecer a la comunidad de productos o servicios trascendentales, ni siquiera para traer de Orihuela dos muelas para los molinos «de aquende» del río Segura, explotados por Antón Abellán que «...non las podia faser traer por quanto non osa sacar de la çibdat moneda alguna que sea de oro, nin de plata, nin otra moneda monedada.." (36); con licencia concejil y dada la importancia de las piezas importadas pudo traer las dos muelas pagándolas con 34 quintales de higos que se le permitió exportar para tal fin, no sin antes haber comunicado la operacioń mercantil al adelantado mayor Juan Sánchez Manuel, en su calidad de alcalde mayor de las sacas que era.

En circunstancias tan difíciles, el proceso de recaudación de aquellos retroactivos dos impuestos aduaneros fue lento y estuvo lleno de incidencias, algunas de las cuales pusieron de manifiesto la intensidad del tráfico mercantil con Orihuela. El primer gran problema lo presentaron a la recaudación los clérigos «...e sus mancebas e paniagudos...», por la razón evidente de sus frecuentes e intensos lazos, intereses y viajes mantenidos con dicha ciudad; el concejo murciano ordenó averiguar cuantos eran los que tenian que pagarlo y en qué proporciones debían hacerlo, pero se encontró con la amena- 
za del obispo de poner a toda la ciudad en entredicho porque el aguacil habia apresado a Pascual Martínez, criado del clérigo Jaime Piquer, vecinos ambos de la parroquia murciana de San Bartolomé, y obligados a pagar 28 y 26 maravedís respectivamente; la negativa de Pascual Martínez a entregar los correspondientes a la segunda imposición, ocasionó su apresamiento y la negativa concejil a entregarlo a la jurisdicción eclesiástica y a la cárcel del obispo, por no sentar un precedente con los demás clérigos de corona. La defensa de los derechos de la Iglesia mantenida con contundencia por el obispo Gumiel (37), impidió la participación de la sociedad eclesiástica en este impuesto al mismo nivel que la laica correspondiente.

En un impuesto en el que se pagaron cantidades variables, entre 1 dobla y 175 doblas (38) como cantidades extremas, tres cuartas partes de los 252 vecinos afectados pagaron entre 1 y 5 doblas, correspondientes al comercio efectuado con las pequeñas cantidades excedentes de sus cosechas o sus ganados o a las modestas transacciones realizadas por artesanos de la ciudad; era este tipo de comercio el que predominaba con respecto al vecino reino de Valencia, no el de los grandes mercaderes, muy pcos, que actuaban preferentemente en el interior de Castilla o de cara a Italia.

De la importancia de este comercio efectuado en territorio aragonés da idea la pormenorizada reglamentación de la "quema» valenciana, efectuada en 1376 (39), en momentos en los que Enrique II sentaba las bases de una política aduanera que alcanzaba las mayores cotas de proteccionismo y control conocidas hasta entonces. El comercio clandestino y el puro trueque fueron las consecuencias directas imposibles de cuantificar, dada la inexistencia de datos al respecto, por razones evidentes de ilegalidad y pequeñez de los volúmenes y los valores más frecuentes. 



\section{NOTAS}

(1) LOPEZ DE AYALA, P. La crónica del rey don Enrique segundo de Castilla, Biblioteca de Autores Españoles, tomo LXVIII, Ediciones Atlas, pág. 3.

2) VALDEÓN BARUQUE, J. Las reformas monetarias de Enrique // de Castilla, en «Homenaje al profesor Alarcos Garciam, Universidad de Valladolid 1965-1966, y Reflexiones sobre la crisis bajomedieval en Castilla, en «Estudios dedicados al profesor don Ángel Ferrari», vol. II, Universidad Complutense, Madrid 1984.

3) Sevilla, 1369-V-11, Archivo Municipal de Murcia (A. M. M.), Cartulario Era 1405-1418, fol. 15-16r., transmitido por CASCALES, F. Discursos históricos de Murcia y su Reyno, Academia Alfonso X El Sabio, Murcia 1980, pág. 157.

4) Sobre los antecedentes de la ceca murciana, TORRES FONTES, J. La ceca murciana en el reinado de Alfonso XI, en «Les Espagnes Médievales. Aspects économiques ét sociaux» Mélanges offerts a Jean Gautier Dalché. Faculté des Lettres et Sciences Humaines de Nice, 1983.

5) A. M. M. Montiel, 1369-1Il-24, Cartulario Era 1405-1418, fol. 15r.

6) BERMÚDEZ AZNAR, A. El proceso de consolidación del Reino de Murcia en la Corona de Castilla (1243-1375), en «Studia Histórica in honorem Vicente Martínez Morellá, Alicante 1985, pág. 16-17.

7) A. M. M. Real sobre Braganza, 1369-X-1, Cartulario Era 1405-1418, fol. 29-30r. y Medina del Campo, 1370-III-27, Cartulario Era 1405-1418, fol. 36.

8) A. M. M. Actas Capitulares Era 1409-1410, fol. 82r. (12-6-1372).

9) A. M. M. Actas Capitulares Era 1409-1410, fol. 59 (8-10-1371) y 66r. (6-12-1371).

10) A. M. M. Burgos, 1372-VIII-12, Cartulario Era 1405-1418, fol. 61.

11) A. M. M. Valladolid, 1371-V-20, Cartulario Era 1405-1418, fol. 69-70r. y 1374-I-6, Act. Cap. Era 1412, fol. 47r. y 48r.

12) MARTÍNEZ CARRILLO, $M \cdot{ }^{a}$ de Los Llanos Manueles y Fajardos, Academia Alfonso X El Sabio 1985.

13) A. M. M. Act. Cap. Era 1409-1410, fol. 24r. (22-7-1371) y 59 (18-10-1371).

14) A. M. M. Act. Cap. Era 1409-1410, fol. 77r. (23-1-1372), MARTínEZ CARRILLO, M. ${ }^{\text {a }}$ de los Llanos Manueles... pág. 88 y sig.

15) A. M. M. Toro, 1373-XI-1 y Castroverde, XII-7, Cartulario Era 1405-1418, fols. 76-79r.

16) GIL FARRES, O. Historia de la moneda española, Diana Artes Gráficas, 1958, pág. 142.

17) A. M. M. Act. Cap. 1417, fol. 154 (5-6-1380)

18) A. M. M. San Esteban de Gormaz, 1379-VII-2, Cartulario Era 1405-1418, fol. 162r. y 1380-VII-1, Cartulario 1384-1391, fol. 133r.

19) 1381-III-12, Cartulario 1384-1391, fol. 52.

20) En $138 \%$, por ejemplo, se escribia al oriolano Pedro Ripoll para que viniese a iMurcia por «...sy podrian fallar en el barato de dinero..., A. M. M. Act. Cap. Era 1419, fol. .7 y sig. (30-11-1381) 
21) GIL FARRES, O. Historia de la moneda..., pág. 141 y RUEDA SABATER, M. El florín: un «dolar» bajomedieval. En «Estudios dedicados al profesor don Ángel Ferrari Núñez», vol. II, Universidad Complutense, Madrid 1984.

22) A. M. M. Act. Cap. 1389, fol. 25 (20-11-1389)

23) A. M. M. Act. Cap. 1384, fol. 73 (26-11-1384), GIL FARRES, O. Historia de la moneda... pág. 216.

24) A. M. M. Act. Cap. 1387 , fol. 46 (30-7-1387)

25) A. M. M. Ávila, 1382-l-12, Cartulario 1384-1391, fol. 44r.

26) A. M. M. Act. Cap. Era 1420, fol. 110 (31-1-1383); Guadarrama, 1383-II-26, Act. Cap. Era 1420 , fol. 141 (17-3-1383) y Cartulario 1384-1391, fol. 63 .'

27) A. M. M. Briviesca, 1387-XII-1, Cartulario 1384-1391, fol. 156, Act. Cap. 1387, fol. 156 $(30-5-1388)$

28) A. M. M. Toro, 1373-XII-22, Act. Cap. Era 1412, fol. 17r. - 18r. y Córdoba, 1375-I-7 y 8, Cartulario Era 1405-1418, fol. 91 y 92 r.

29) MENJOT, D. Las aduanas del reino de Murcia en el siglo XIV, en «Fiscalidad y sociedad», Academia Alfonso X El Sabio 1986, pág. 328.

30) A. M. M. Act. Cap. 1374, fol. 180r. (18-5-1375)

31) A. M. M. Act. Cap. 1374, fol. 154 y sig.

32) A. M. M. Act. Cap. Era 1412, fol. 62r. (24-9-1374)

33) A. M. M. Act. Cap. Era 1412, fol. 71. (30-10-1374), 85 (8-12-1374), 100r. (16-12-1374) y $144(13-3-1375)$

34) A. M. M. Segovia, 1374-VIII-31, Cartulario Era 1405-1418, fol. 86r.

35) A. M. M. Segovia, 1374-X-2, Cartulario Era 1405-1418, fol. 85 y Act. Cap. Era 1412, fol. $78 \mathrm{r} .(5-11-1374)$

36) A. M. M. Act. Cap. Era 1412, fol. 110 (17-1-1375)

37) A. M. M. Act. Cap. 1375, fol. 29r. y sig. (20-8-1375). TORRE FONTES, J. Tres obispos y un obispillo, en «Murcia Medieval. Testimonio documental |l», Murgetana 53, 1978.

38) MARTÍNEZ CARRILLO, M. ${ }^{a}$ de los Llanos. Las aduanas murcianas en el reinado de Enrique II, en cHomenaje al profesor Juan Torres Fontes», Univ. de Murcia, Academia Alfonso $X$ el Sabio, 1987.

39) A. M. M. Act. Cap. Era 1413, fol. 83r. (5-2-1376). PASCUAL MARTINEZ, L. Notas para el estudio de una institución: el alcalde-comisario de la frontera castellano-aragonesa, Miscelánea Medieval Murciana II, 1976 